\title{
Extracellular pH, osmolarity, temperature and humidity could discourage SARS-CoV-2 cell docking and propagation via intercellular signaling pathways
}

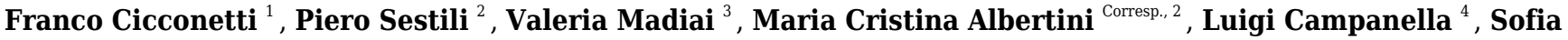 \\ Coppari $^{2}$, Daniele Fraternale ${ }^{2}$, Bryan Saunders ${ }^{5,6}{ }^{\text {, }}$ Laura Teodori $^{3}$ \\ ${ }^{1}$ Department of Emergency DEA - Surgery, University of Roma "La Sapienza", Rome, Italy \\ Department of Biomolecular Sciences, University of Urbino, Urbino, Italy \\ 3 Laboratory of Diagnostics and Metrology, FSN-TECFIS-DIM, ENEA, Frascati-Rome, Italy \\ 4 Department of Chemistry, University of Roma "La Sapienza", Rome, Italy \\ 5 Applied Physiology and Nutrition Research Group, Universidade de São Paulo, São Paulo, Brazil \\ 6 Institute of Orthopaedics and Traumatology, Faculty of Medicine FMUSP, Universidade de São Paulo, São Paulo, Brazil \\ Corresponding Author: Maria Cristina Albertini \\ Email address: maria.albertini@uniurb.it
}

The COVID-19 pandemic and its virus variants continue to pose a serious and long-lasting threat worldwide. To combat the pandemic, the world's largest COVID-19 vaccination

campaign is currently ongoing. As of July $19^{\text {th }} 2021,26.2 \%$ of the world population has received at least one dose of a COVID-19 vaccine (1.04 billion), and 1 billion has been fully vaccinated, with very high vaccination rates in countries like Israel, Malta, and the UEA. Conversely, only $1 \%$ of people in low-income countries have received at least one dose with examples of vaccination frequency as low as $0.07 \%$ in the Democratic Republic of Congo. It is thus of paramount importance that more research on alternate methods to counter cell infection and propagation is undertaken that could be implemented in low-income countries. Moreover, an adjunctive therapeutic intervention would help to avoid disease exacerbation in high-rate vaccinated countries too. Based on experimental biochemical evidence on viral cell fusion and propagation, herein we identify i) extracellular $\mathrm{pH}(\mathrm{epH})$, ii) temperature, and iii) humidity and osmolarity as critical factors. These factors are here in discussed along with their implications on mucus thick layer, proteases, abundance of sialic acid, vascular permeability and exudate/edema. Heated, humidified air containing sodium bicarbonate has long been used in the treatment of certain diseases, and here we argue that warm inhalation of sodium bicarbonate might successfully target these endpoints. Although we highlight the molecular/cellular basis and the signalling pathways to support this intervention, we underscore the need for clinical investigations to encourage further research and clinical trials. In addition, we think that such an approach is also important in light of the high mutation rate of this virus originating from a rapid
Peer) reviewing PDF (2021:05:61344:1:1:NEW16 Aug 2021) 
increase. 


\section{Extracellular pH, osmolarity, temperature and humidity could discourage SARS-CoV-2 cell docking and propagation via intercellular signaling pathways}

Franco Cicconetti ${ }^{1}$, Piero Sestili ${ }^{2}$, Valeria Madiai ${ }^{\circ}$, Maria Cristina Albertini², Luigi Campanella ${ }^{4}$, Sofia Coppari $^{2}$, Daniele Fraternale ${ }^{2}$, Bryan Saunders ${ }^{5,6 \#}$ and Laura Teodori ${ }^{3 \#}$

\footnotetext{
1. Department of Emergengy DEA - Surgery, University of Roma "La Sapienza”, Rome, Italy

2. Department of Biomolecular Sciences, University of Urbino, Urbino, Italy

3. Laboratory of Diagnostics and Metrology, FSN-TECFIS-DIM, ENEA, Frascati-Rome, Italy

4. Department of Chemistry, University of Roma "La Sapienza”, Rome, Italy

5. Applied Physiology and Nutrition Research Group, Universidade de São Paulo, São Paulo, Brazil

6. Institute of Orthopaedics and Traumatology, Faculty of Medicine FMUSP, University of São Paulo, Brazil
}

5

- ENEA Visiting researcher

\# equally contributed

9

Corresponding Author:

Maria Cristina Albertini

Email address: maria.albertini@uniurb.it

\section{Abstract}

The COVID-19 pandemic and its virus variants continue to pose a serious and long-lasting threat worldwide. To combat the pandemic, the world's largest COVID-19 vaccination campaign is currently ongoing. As of July $19^{\text {th }} 2021,26.2 \%$ of the world population has received at least one dose of a COVID19 vaccine (1.04 billion), and 1 billion has been fully vaccinated, with very high vaccination rates in 
countries like Israel, Malta, and the UEA. Conversely, only 1\% of people in low-income countries have received at least one dose with examples of vaccination frequency as low as $0.07 \%$ in the Democratic Republic of Congo. It is thus of paramount importance that more research on alternate methods to counter cell infection and propagation is undertaken that could be implemented in low-income countries. Moreover, an adjunctive therapeutic intervention would help to avoid disease exacerbation in high-rate vaccinated countries too. Based on experimental biochemical evidence on viral cell fusion and propagation, herein we identify i) extracellular $\mathrm{pH}(\mathrm{epH})$, ii) temperature, and iii) humidity and osmolarity as critical factors. These factors are here in discussed along with their implications on mucus thick layer, proteases, abundance of sialic acid, vascular permeability and exudate/edema. Heated, humidified air containing sodium bicarbonate has long been used in the treatment of certain diseases, and here we argue that warm inhalation of sodium bicarbonate might successfully target these endpoints. Although we highlight the molecular/cellular basis and the signalling pathways to support this intervention, we underscore the need for clinical investigations to encourage further research and clinical trials. In addition, we think that such an approach is also important in light of the high mutation rate of this virus originating from a rapid increase.

\section{Introduction}

The COVID-19 pandemic caused by the SARS-CoV-2 virus is currently afflicting the world population. The scenario epidemiologists are constructing is unfortunately forecasting a long stay (Scudellari, 2020). COVID-19 infection often leads to severe acute respiratory syndromes. However, extra pulmonary manifestations have also been described e.g. hematologic, gastroenterological, renal, dermatologic, neurologic, and psychiatric complications (AlSamman et al., 2020). Indeed, it is now clear that this disease may turn into a dangerous systemic one involving several organs, which might become symptomatic even after the virus becomes inactive. To contain and combat the pandemic, the world's largest COVID-19 vaccination campaign is underway ("Coronavirus disease (COVID-19): Vaccines"), although the organizational machinery for vaccine supply, access and administration is not without issue, and several setbacks have occurred in several countries.

\section{Global outlook}

As of July $19^{\text {th }}$ there were 562,547 new daily cases and 10,779 new deaths worldwide. Furthermore $26.2 \%$ of the world population has received at least one dose of a COVID-19 vaccine (1.04 billion), whereas 1 billion have been fully vaccinated, with very high rates in countries like Israel, Malta, the UEA. Conversely, only $1 \%$ of people in low-income countries have received at least one dose with examples of vaccination frequency as low as $0.07 \%$ in the Democratic Republic of Congo ("COVID Live 
Update: 199,614,894 Cases and 4,249,394 Deaths from the Coronavirus - Worldometer") Graphical representation of vaccination progress is accessible e.g. at Our World In Data (Ritchie et al., 2020). It is thus of paramount importance that more research on alternate methods to counter the COVID-19 disease is undertaken and that can be implemented in low income countries. Furthermore, as breakthrough infections and infections from virus variants are occurring even in countries with good vaccination rates, the study of adjunctive therapeutic interventions is of paramount importance. It is also too early to know the duration of protection of COVID-19 vaccines, and more research need to be done on the vaccination efficacy on variants (Harvey et al., 2021). Due to the high rate of mutations and emerging new variants, vaccines may need to be adapted to ensure protection. Some data raise concerns on the level of protection provided by COVID-19 vaccines against some variants (Focosi \& Maggi, 2021; Krishnan \& Krishnan, 2021; LL et al., 2021; A et al., 2021)- Amino acid substitutions in the spike protein (S-protein) are an important virus strategy to evade the host immune response. Indeed, if the mutation is in the antigenicity region of the $\mathrm{S}$ protein, this may allow viruses to escape host antibodies and the genetic drift may represent a way for the virus to maintain its diffusion in the human population. Whether genetic variations affect the related antigenic phenotype will need to be confirmed by antigen analyses, using $\mathrm{S}$ genes with such mutants (Ren et al., 2015). Thus, SARS-CoV-2 entry inhibitors have an important role against COVID-19 and research on therapeutic approached to that work alongside the vaccines are still needed.

In this scenario, the discovery of cheap and easily available medical devices that could help to prevent or ameliorate COVID-19 symptoms, thus avoiding advanced cases clogging the sanitary structures and intensive-care-units, would be a great resource. In addition, oxygen therapy intubation and mechanical ventilation is required when respiratory failure occurs, especially in compromised patients, and this may yield considerable health risks and higher frequency of death. (LD et al., 2008; Khan et al., 2020). The need for an accessible, economical and easy to handle approach is important as the pandemic is increasingly overwhelming the planet. Understanding virus behavior in relation to $\mathrm{pH}$ levels, temperature and other micro environmental factors is of paramount importance for virus inactivation and attenuation, vaccine formulation and quality control, and drug targeting (Scheller et al., 2020). Thus SARS-CoV-2 entry inhibitors have an important role and COVID-19 and the research on therapeutics approach are still needed, to work alongside the vaccines and other drugs approaches (Dong et al., 2021).

\section{Background and Scientific Rationale}

We have focused our review on the biochemical, physiological and physical cellular mechanism via which $\mathrm{pH}$, osmolarity, humidity and temperature changes modulate the micro-environmental airway tract in limiting virus infection and proliferation, with the ultimate goal to discourage virus infection and 
100

101

102

103

104

105

106

107

108

109

110

111

112

113

114

115

116

117

118

119

120

121

122

123

124

125

126

127

128

129

130

131

modulate the cellular response against virus infection. One of the possible approaches to modulate airway environment is warm inhalation with sodium bicarbonate (SB). SB at $8.4 \%$ concentration is an alkaline solution of approximately $8.5 \mathrm{pH}$, and is an alkalinizing agent widely used in the treatment of metabolic acidosis ("Sodium Bicarbonate Injection Information - Drugs.com”; Integrated Biomedical Technology) (see below). Although no consensus currently exists on the utility of alkaline therapy for respiratory acidosis, very little attention remains dedicated to this approach. Undoubtedly, controlled studies are necessary to test the efficacy and efficiency of alkaline therapy to establish the optimal mode of administration (dose, rate, and tonicity). However, most of the controversies on alkaline therapy are based on intravenous administration of SB (Chand, Swenson \& Goldfarb, 2021).

Based on experimental data, we have outlined the cellular/molecular mechanisms that work against the virus in the presence of SB warm vapour. This intervention could be a highly valuable, safe, welltolerated and cost-effective treatment as reported below, although clinical information is scarce regarding the potential application of such an approach, thus researchers may be unaware of its potential as an adjunct preventive treatment in the fight against COVID-19. Therefore, herein we provide appropriate information from the literature to provide a theoretical basis to propose SB warm inhalation therapy as a worthwhile tool for further investigation in the fight against COVID-19. To the best of our knowledge, few clinical trial has been performed ("The Role of Sodium Bicarbonate as Adjuvant Treatment of Computed Tomography Identified COVID-19 Pneumonia - Full Text View - ClinicalTrials.gov"; Mody, 2020), although trials exist for other pathologies. Results of SB clinical trials (although not via inhalation) for acidosis-associated diseases, such as. diabetes, severe dehydration and renal insufficiency, have been reported (Melamed et al., 2020; Quade, Parker \& Occhipinti, 2021). At present, SB inhalation can be used as a therapeutic agent in the treatment of acidosis caused by cystic fibrosis (CF) (Gomez et al., 2020). The study reports that inhalation of aerosolized SB on 12 CF volunteers is secure (no side effects were evidenced) and well tolerated even at the highest dose ( $5 \mathrm{~mL}$ saturated solution, $\mathrm{pH} 8.4 \%$, twice a day). The benefits of inhaled $\mathrm{NaHCO}_{3}$ are due to the increase of $\mathrm{pH}$ of the airway surface liquid (sputum rheology improvement, sputum viscosity and viscoelasticity reduction). These changes may be responsible of enhancing the respiratory immune defense favoring mucociliary clearance to maintain airway hygiene. Other studies have demonstrated that the use of hypertonic saline solution is an inexpensive, safe, and effective additional therapy in CF patients (LM \& RJ, 2007). Recently, an in vitro study provided molecular evidence that SB may have a direct therapeutic effect on the bronchial epithelium (Gróf et al., 2020) while confirming the safe therapeutic use of inhaled sodium bicarbonate. A clinical study on COVID-19 (Wardeh, Conklin \& Ko, 2020) reported a significant improvement of 
132 COVID-19 patients after SB inhalation. Improved clinical parameters were observed also in another

133 clinical study (Mody, 2020).

134 As with other viral infections, SARS-CoV-2 and their variants thrive in specific environmental conditions

135 that optimize virus fusion. A mechanistic explanation of why the therapeutic approach of SB warm

136 inhalation may provide a hostile and detrimental environment for the virus is discussed herein. SB-

137 modulated environmental factors which affect viral fusion include i) external $\mathrm{pH}(\mathrm{epH})$, ii) temperature,

138 iii) humidity and osmolarity. These factors are discussed along with their implications on mucus thick

139 layer, proteases, abundance of sialic acid, vascular permeability and exudate/edema.

\section{Survey methodology}

142 Papers found in Pubmed describing cellular/molecular mechanisms to support the use of warm SB 143 inhalation were considered. In particular, whenever available, data focused on chemical/physical features 144 such as $\mathrm{pH}$, osmolarity, and humidity involved in SARS-CoV2 docking, replication and propagation steps 145 were included, together with the activated cell signaling. In case no published data on SARS-Cov2 were 146 available, results regarding other coronaviruses or similar viruses were discussed. Additionally, due to the 147 overwhelming publication rate, we also consulted the new COVID-19 platform resource, CoronaCentral Dashboard (https://coronacentral.ai/) (https://www.pnas.org/content/118/23/e2100766118) (Lever \& Altman, 2021).

Papers with controversial, conflicting and opposing opinions/data were also considered to provide a comprehensive and balanced overview.

\section{Increased external pH may disadvantage virus infection}

Extracellular $\mathrm{pH}(\mathrm{epH})$ affects many cellular/molecular structures including lipid bilayers (YAMAGUCHI et al., 1982; Angelova et al., 2018), protein expression (ER, 1993) and even intracellular $\mathrm{pH}$ (Fellenz \& Gerweck, 1988). pH is a critical factor whose change gives rise to significant alterations in the protein structure. Conformational change of viral proteins involved in docking and replication in the host cell could yield virus inactivation. Indeed, epH is one of the most important environmental conditions influencing a virus's infection (S, CJ \& OD, 1991; JL et al., 2009; MH et al., 2014; Badrawy \& El-Khier, 2018; Stancioiu et al., 2020). Cell membranes fusion of to the influenza virus is promoted by an appropriate acidic epH depending on the virus (Helenius, 2013).

162 SARS-CoV-2 shares many of the characteristics of coronavirus and the general mechanism for SARS163 CoV-2 infection has been identified on the basis of knowledge of the other SARS-CoV and MERS-CoV. 164 In particular, coronaviruses are stable at $\mathrm{pH} 6.0$ and $37^{\circ} \mathrm{C}$ (half-life 24 hours), but are quickly and 
165 permanently inactivated by short-term treatment at $\mathrm{pH} 8.0$ and $37^{\circ} \mathrm{C}$ (half-life 30 minutes) (Sturman, 166 Ricard \& Holmes, 1990).

167 Low $\mathrm{pH}$ is necessary for conformational changes (activation) of viral-glycoproteins (Dollery, Delboy \& 168 Nicola, 2010; Yuan et al., 2018). The S glycoprotein protein is the "viral armed wing" of a glycoprotein. 169 Proteolytic activation of viral glycoproteins by endosomal proteases also needs low pH (Yuan et al., 170 2018). It is well known that the first stage of infection for Coronaviridae is S-protein-mediated 171 attachment to the cell surface receptor. However, SARS and other human coronaviruses may use 172 redundant mechanisms for cell docking e.g. ACE2, N-acetyl-9-O-acetyl neuraminic acid (sialic acid: SA) 173 moieties and heparan sulphate, thus many recent studies focused on molecular modelling of SARS-CoV2174 host docking. Many of these docking mechanisms are $\mathrm{pH}$ dependent. So far, studies show that SARS175 CoV-2 uses the ACE2 receptor as a main docking protein (Yang et al., 2020; Teodori et al., 2020). ACE2 176 is essential for SARS-CoV-2 fusion, but it is uncertain whether ACE2 interactions are enough for SARS177 CoV-2 binding. ACE2 is probably necessary for the entry of the virus but might not be the unique or 178 primary cell surface binding site. Heparan sulfate proteoglycans act as adhesion molecules, perhaps making the interaction between SARS-CoV-2 and ACE2 easier. Thus, infection modalities are more complicated than so far reported and a more appropriate knowledge of the infection process is necessary for new drug discoveries (Gallagher et al., 2013; Zamorano Cuervo \& Grandvaux, 2020).

182 Sialic acids (SAs) are an important class of receptors for several human viruses infection, including 183 SARS-CoV binding to respiratory tract epithelium cells (Bouvier \& Palese, 2008). SA-receptors are also 184 important for CoVs docking, and the binding of the virus to the host cell are $\mathrm{pH}$-mediated (pH 5-6). 185 Recently, it has been demonstrated that the S-protein from SARS-COV-2 binds SAs (Baker et al., 2020; 186 Milanetti et al., 2020). Adequate virus-membrane fusion (i.e fusion pore efficient forming and 187 delivery/transport of the viral RNPs into the nucleus) is necessary for new viral RNA replication, 188 transcription and translation of the viral proteins and formation of new viruses.

189 For several viruses, acidification of the capsid is critical for viral entry. In these cases, viral capsids show 190 protease active sites sensitive to $\mathrm{pH}$. In addition, acidic $\mathrm{pH}$ similar to endosomes' $\mathrm{pH}$ induces a structural 191 change in the capsid that induces autolytic protease activity and this pH-dependent protease activity may 192 be important for viral infection (Salganik et al., 2012). The $\mathrm{pH}$-activated proton-selective channel M2 also 193 has an important role in virus replication (Takeda et al., 2002). The M2 proton channel responds to epH; 194 specifically, low epH activates the channel and high epH closes the channel. M2 mediates membrane 195 scission during the budding of influenza viruses (Holsinger et al., 1994). During infection, increased 196 glycolytic activity of infected cells produces an increased release of $\mathrm{H}^{+}$from the infected cells endosomes 197 through the viral M2 $\mathrm{H}^{+}$channel, leading to a lowered epH at the cell-surface (Liu et al., 2016). These 198 mechanisms support viral reproduction. To our knowledge, no investigations exist on ion-transmembrane- 
199

200

201

202

203

204

205

206

207

208

209

210

211

212

213

214

215

216

217

218

219

220

221

222

223

224

225

226

227

228

229

230

231

232

exchange-proteins modulation in SARS-CoV-2, although this is an interesting topic to explore. Indeed, diseases of ion channel function, such as cystic fibrosis, lead to dysregulated fluid levels in various lung compartments, and these diseases are often associated with pulmonary infection (Rowe, Miller \& Sorscher, 2005). Protease machinery is also highly epH-dependent, as in the case of TMPRSS2 (transmembrane-protease-serine-2) for S-protein priming. The TMPRSS2 is a proteolytic enzyme that forms part of the ACE2 receptor and has been identified as fundamental. TMPRSS2 acts on protein S at the S1 / S2 cleavage site, detaching the S1 subunit and thus ensuring fusion with the cell membrane. The proteolytic cut causes a conformational change that causes the protein to open, resulting in the fusion peptide approaching the cell membrane. Subsequently, the S2 subunit of the S protein, closes on itself, causing the formation of a pore which leads to the completion of fusion (Nieto-Torres et al., 2014).

TMPRSS2 virus entry can be blocked by inhibitors of cellular TMPRSS2 (Yamaya et al., 2016). TMPRSS2 might also promote viral diffusion and pathogenesis by diminishing viral neutralizing antibodies recognition and activating CoV S-protein for virus-cell fusion (Glowacka et al., 2011). TMPRSS2 is present in airway epithelial cells; it triggers the fusion of the viral and endosomal membranes and has an optimal activity at acidic $\mathrm{pH}$. Priming of S-proteins by target cell proteases is fundamental for viral entry and cleavage at the S1/S2 and the S2' sites. The S1/S2 cleavage site of Sprotein fosters many arginine residues, indicating a high cleavability. Noteworthy, the cleavage site sequence can determine the coronaviruses zoonotic potential. Indeed, host TMPRSS2 involvement in viral diffusion has been described for COVID-19 (Mollica, Rizzo \& Massari, 2020; Zipeto et al., 2020).

In addition to the influence of epH on SAs-receptor docking, it can modify SA activity. Virus neuraminidase (NA), a sialidase that is one of the major surface glycoproteins of influenza viruses, needs an acidic environment to degrade SAs. The importance of SAs on SARS-CoV-2 has been shown (Kim, 2020). Due to the ubiquitous distribution and location of SAs, they modulate many cellular functions and pathological processes. SAs are also the binding targets of a great number of pathogenic organisms and their toxins. NA and hemagglutinin are two relevant virus antigens. The main functions of NA are the cleavage of SAs from the host cells surface, aiding in the release of the new virus produced by the infected cells and aiding virus transport through the sialated mucus, present in the airway tract. Although there is scant information on the binding affinity of SAs and NA, SA-binding and NA-cleavage are important factors for infection progression. Both acidic epH and physiological temperature are necessary for good NA enzymatic activity (Garcia et al., 2014).

Other studies suggest a host-variable protective role of SAs in secreted mucus (Zanin et al., 2016). Respiratory mucus traps and neutralizes viruses (Eccles, 2020). Pathogen binding can be blocked by soluble mucins, secreted into airways which contain large quantities of SAs. This complexity needs to be considered to understand the $\mathrm{CoV}$ pathogenesis processes. 
233 Little attention has been paid to the influence of epH on the immune response (Kellum, Song \& Li, 2004).

234 Environmental $\mathrm{pH}$ influences multiple immunological functions, unravelling an interplay between epH

235 and immune cells (Díaz, Dantas \& Geffner, 2018). Extracellular acidosis is a hallmark of the 236 inflammation processes. Accumulation of protons in the extracellular environment is associated with the 237 inflammatory course. High concentrations of protons are recognized by innate immune cells as a "danger238 associated molecular pattern" (Casimir et al., 2018). Recent evidence suggests links between acid-base 239 balance and cytokine concentrations, with a certain level of acidosis triggering the inflammatory 240 condition. When acute infection is activated, the phagocyte-based innate immune system plays a 241 fundamental role since, the proton concentration may provoke inflammation (Casimir et al., 2018). 242 Proton-sensing G protein-coupled receptors (e.g. GPR4) are important for $\mathrm{pH}$ homeostasis and 243 inflammation control (JA, 2002). Higher expression of GPR4 is observed in patients with inflammatory 244 disease (e.g. bowel inflammation (Vallière et al., 2015). GPR4 is upregulated by an acid epH and 245 downregulated at $\mathrm{pH}$ 7.4, with very little activity observed at a more alkaline pH (e.g. >7.4) (Chen et al., 246 2011; Dong et al., 2013). Increased expression of many inflammatory genes (e.g. chemokines, cytokines, 247 adhesion molecules, nuclear factor kappa B pathway genes, prostaglandin-endoperoxide synthase 2, and 248 stress response genes) is observed when GPR4 is over activated. Acidosis, together with other environmental factors, may act as a regulator of the immune response able to induce a pro-inflammatory or a pro-resolving immune response depending on the context (Díaz, Dantas \& Geffner, 2018).

251 Many stages in the viral replication life cycle are dependent on a low epH, and the SARS-CoV-2 virus 252 appears no different. Thus, to combat viral progression, inhalation of aerosolized SB could be an 253 interesting preventive tool since it will increase the epH creating an inhospitable environment for virus 254 docking and replication. There are several experimental studies on the influence of epH and modification 255 of cell signalling and cell physiology that are connected with virus infection, thus supporting our 256 hypothesis. Studies on SARS-COV-2 infection and epH are currently ongoing and slowly being 257 published. A recent paper with the same hypothesis has now been published (B, 2021), further 258 strengthening our proposal. Indeed, the authors hypotize that enriching the environment of several 259 negatively charged ions, including e.g. $\mathrm{O}_{2}^{-}, \mathrm{O}_{-}^{-}, \mathrm{O} 3-, \mathrm{CO} 3-, \mathrm{HCO} 3-, \mathrm{NO}^{-}-\mathrm{NO} 2-$, and $\mathrm{OH}_{-}^{-}$, thus 260 increasing epH, would discourage virus fusion. Nonetheless, we believe the benefits of warm SB 261 inhalation is not exclusively on epH changes, but also other physicochemical characteristics such as 262 humidity and temperature, as reported below.

\section{Increased extracellular temperature may disadvantage virus infection}


265 Together with $\mathrm{pH}$, temperature is another innate physiological barrier against infections. Many 266 microorganisms do not survive beyond certain temperatures. In addition, temperature exerts substantial 267 mechanical and biochemical effects on the airway epithelium.

268 The lung tissue represents the largest surface area of the human body exposed to the external environment 269 (Karamaoun et al., 2018). A large area of the bronchial epithelium is sheltered by a mucus layer to protect 270 against foreign particles and pathogens. This mucus layer and periciliary layer are thick gel-like 271 substances made of water and mucins. The cilia present in the epithelium, by beating metachronously in 272 the pericilia layer, can transfer the mucus to the top of the trachea to be cleared. This mucociliary 273 transport and clearance is a fundamental defense mechanism of the lungs against invading pathogens and 274 is a major first line of defense against respiratory pathogens. Many pulmonary diseases are associated 275 with an impairment of the mucociliary clearance and accumulation of mucus in airway lumen. Although 276 several aspects of the bronchial mucus dynamics still remain unclear, it has been shown that the temperature and relative humidity (discussed below) of the inspired air can influence the efficiency of mucus clearance (Saketkhoo, Januszkiewicz \& Sackner, 1978; Boucher et al., 1981; Williams et al., 1996; Karamaoun et al., 2018). Temperature in the respiratory tract is an important environmental factor influencing virus infection and host reaction. For example, some common cold viruses (e.g. rhinovirus) replicate more efficiently at $33-35^{\circ} \mathrm{C}$ than at $37^{\circ} \mathrm{C}$ temperatures of the nasal cavity environment. A less robust interferon (IFN) and IFN-stimulated-gene response is observed in respiratory epithelial cells at cool temperatures (Foxman et al., 2015). Indeed, higher temperature induces higher expression of type I and type III IFN genes and IFN-stimulated-genes in host cells of the respiratory tract resulting in a generalized antiviral resistance. $\mathrm{CoV}$ induces a higher IFN-dependent innate immune response at $37^{\circ} \mathrm{C}$ than at $33^{\circ} \mathrm{C}$. Experimental data demonstrate that SARS-CoV-2 also induces type I IFN expression following infection of macrophages. Other investigations have shown that induction of temperaturedependent IFN following rhinovirus infection depend on the mitochondrial antiviral-signaling (MAVS) protein, a key signalling adaptor of the RIG-I-like receptors. RIG-I is a sensing molecule able to distinguish viral dsRNA from host dsRNA. Once the sensor is activated, it interacts with MAVS (mitochondrial antiviral) which, once activated, continues the signalling cascade through the kinases TBK1 and IKKe. In addition, IKKe signalling also induces many IFN-inducible proteins via the STAT1 pathway. The genes induced in response to IFN- $\beta$, trigger the cell to block virus replication and induce antiviral protein secretion in response to secreted IFN (Frieman \& Baric, 2008). Some studies have also demonstrated that SARS-coronavirus suppresses innate immunity by mitochondria and targets MAVS/TRAF3/TRAF6 signalling. This severely limits host cell IFN responses (Shi et al., 2014). IFN exerts its antiviral effects by inducing more than 300 IFN-stimulated genes with diverse antiviral 
298 functions. SARS-CoV-2 infected cells have an impaired interferon response suggesting that the virus

299 disrupts the normal host cell interferon response (Schneider, Chevillotte \& Rice, 2014).

300 Advanced-stage COVID-19 patients with respiratory symptoms undergo oxygen ventilation (Grasselli et 301 al., 2020). This exposes patients to the inhalation of cold air which produce pro-inflammatory substances 302 (D'Amato et al., 2018). Exposure to cold air increases macrophage and granulocyte numbers in the lower 303 airway tract (Larsson et al., 1998). Moreover, cold-related dysregulation of respiratory mucociliary 304 function inhibits microorganisms and pollutants clearance (Clary-Meinesz et al., 1992). Thus, in addition 305 to its effects on epH, warm SB inhalation might provide a sub-optimal environmental temperature for 306 virus replication and serve to improve some of the respiratory mucociliary function impairment associated 307 with cold air inhalation. Intubation/ventilation may be overused for COVID-19 patients and simpler and 308 more widely available devices are desirable which can similarly treat early-stage patients to avoid disease 309 progression and mitigate symptoms.

310 Throughout the preparation of this review paper, trials using steam inhalation for thermal inactivation of

311 SARS COVID-2 virus are being conducted and providing encouraging results (G et al., 2021).

312

\section{Increased external humidity and osmolarity may disadvantage virus infection}

314 Virus survival and transmission also depend on humidity. Indeed, humidity and water exchange between 315 mucus and inhaled/exhaled air (evaporation/condensation) also influence mucociliary clearance alone or 316 in conjunction with temperature (Bustamante-Marin \& Ostrowski, 2017). It is well-known that as the air 317 became drier, mucociliary clearance slows. The influence of humidity levels on the mucous membrane 318 environment in animal models has been investigated in vitro at several temperatures, showing that the 319 mucociliary wave frequency was decreased in reduced environment humidity from $90 \%$ to $20 \%$ (Mercke, 320 1975).

321 Pathologic processes of the upper-respiratory-tract (mucosal congestion and edema) could be influenced 322 by mucosal microcirculation modulation controlling hypertonicity. Reasonable evidence shows that the 323 airway epithelium fluid layer is exposed to changes in tonicity. Abnormalities in the homeostasis of the 324 airway surface liquid layer lead to consequent failure in maintaining an adequate lung defense. Abnormal 325 airway surface fluid respiratory tract epithelia fail to kill bacteria. Hypertonic saline affects mucociliary 326 clearance and clinical outcomes in chronic bronchitis (Wark \& Mcdonald, 2018; Bennett et al., 2020). 327 Together with the biochemical effects described above, SB warm inhalation may also provide a physical 328 effect as an osmotic pump. SB warm inhalation may create favorable osmotic conditions to repair 329 damages from oxygen demand. The inhalation of steam may alleviate the constriction of lung and air 330 sacs, allowing mucus and organisms to move out of the lungs more readily, and allow oxygen to diffuse 
331 into the lungs more efficiently. In a review of 19 trials, that hypertonic saline solution (HS) (nebulised as

332 a fine mist through a mask or mouthpiece) appeared to be an effective adjunct therapy during acute 333 exacerbations of lung disease in adults (Wark \& Mcdonald, 2018). In another study, inhaled HS was 334 delivered to people with CF to promote mucus clearance via an increased ionic strength (Alaiwa et al., 335 2016). Ongoing research using steam inhalation therapy with the addition of natural products against 336 COVID-19 are also being published (Chakraborty \& Daniel, 2020; G et al., 2021; S et al., 2021).

337 Warm SB steam inhalation therapy may be considered a safe medical device against COVID-19 338 progression provided that some conditions are followed to avoid irritation or scalding injuries, although 339 these are very unlikely (WL et al., 1991). Approximately $1 \mathrm{~L}$ of water should be brought to the boil before 340 adding $20 \mathrm{~g}$ of SB. After turning off the heat, the head of the patient should be placed $30-40 \mathrm{~cm}$ above the 341 solution and covered with a cloth. The individual should then breath normally for 15 min (Figure 1). This 342 therapy may be used as pre-exposure/exposure prophylaxis, as adjunctive therapy (either during SARS343 COV2 infection and COVID-19 disease progression) or added in oxygen ventilator devices for severe 344 COVID-19 patients. This protocol should be implemented twice daily (Figure 2).

\section{Conclusion}

346 Herein we have illustrated a rationale for combatting COVID-19 by modulating the physicochemical microenvironment of the airway tissue which represents the first route of virus infection. One method of achieving such a micro-environmental modulation is through the administration of nebulized warm SB inhalation.

This proposal is in line with the "COVID Action Platform" of the World Economic Forum to perform new evidence-based approaches: "to potentially mitigate the risk" ("COVID Action Platform | World Economic Forum"). Indeed, this approach might represent a pleiotropic adjunctive strategy to limit SARS-CoV-2 infection/ replication and disease progression within host airways. Based on the molecular/cellular evidence herein above, warm SB inhalation could be provided as a valuable preventive prophylaxis alongside other preventive approaches. Such an approach could also be administered in the therapy, appropriately modifying the ventilation devices

Most importantly, we highlight the possibility that SB warm inhalation could discourage virus host cell adhesion and proliferation and avoid that the harshest outcome of the disease occurs. Indeed, SB warm inhalation creates a hostile physicochemical environment to undermine virus stability. 
362 Warm SB inhalation currently remains a poorly explored, yet potentially underrated and underappreciated

363 option that warrants further study, but and it could yet play an important role in the fight against COVID-

36419 disease progression. Indeed, further studies are needed to prove thatmodulating these cellular 365 biochemical/physical features could be efficacious and safe against COVID-19 in vivo. Studies with CF

366 suggest this therapy to be safe, although too few studies are available to quantify the effectiveness of this

367 intervention, but the few reported above are encouraging. Early and timely treatment with therapeutic

368 regimens controlling virus replication and inflammation might help to modify the course of disease

369 progress, improve patients' recovery rate and time, ultimately avoiding the risk of hospital collapse sadly

370 experienced even by most western countries. SB inhalation can easily be performed in a domiciliary care

371 setting and could reasonably fulfil the extraordinarily urgent need for early, simple and cost-friendly

372 interventions. Simple SB inhalation may be effective to prevent or mitigate COVID-19 symptoms. This

373 virtually cost-free modality would appreciably benefit the general population, not only for pre-exposure

374 prophylaxis, but also in protecting against SARS-CoV-2 antigenic drift and future virus pandemics. 


\section{Acknowledgments}

377 The authors would like to warmly thank Prof. Bruno Gualano from

378 the Applied Physiology \& Nutrition Research Group, School of Medicine,

379 University of Sao Paulo (Brazil), for his generous contribution to the manuscript. Bryan Saunders has

380 been financially supported by Fundação de Amparo à Pesquisa do Estado de São Paulo (2016/50438-0)

381 and a grant from Faculdade de Medicina da Universidade de São Paulo (2020.1.362.5.2). There was no 382 additional external funding received for this study.

383 The authors would also like to thank Fausto Tili (Terme Francescane srl, Spello-PG, Italy) for his advice 384 on bicarbonate water inhalation therapies. 
386

387

388

389

390

391

392

393

394

395

396

397

398

399

400

401

402

403

404

405

406

407

408

409

410

411

412

413

414

415

416

417

418

419

\section{References}

A B, F N, FD F, A G, G C, M P, A C, R C, C Z, R P, A T, A R, E T, G C, D F, L M, F M. 2021. Introduction of SARS-COV-2 C.37 (WHO VOI lambda) from Peru to Italy. Journal of medical virology:jmv.27235. DOI: 10.1002/JMV.27235.

Alaiwa MHA, Launspach JL, Sheets KA, Rivera JA, Gansemer ND, Taft PJ, Thorne PS, Welsh MJ, Stoltz DA, Zabner J. 2016. Repurposing tromethamine as inhaled therapy to treat CF airway disease. JCI Insight 1. DOI: 10.1172/JCI.INSIGHT.87535.

AlSamman M, Caggiula A, Ganguli S, Misak M, Ali Pourmand. 2020. Non-respiratory presentations of COVID-19, a clinical review. American Journal of Emergency Medicine 38. DOI: 10.1016/j.ajem.2020.09.054.

Angelova MI, Bitbol AF, Seigneuret M, Staneva G, Kodama A, Sakuma Y, Kawakatsu T, Imai M, Puff N. 2018. pH sensing by lipids in membranes: The fundamentals of $\mathrm{pH}$-driven migration, polarization and deformations of lipid bilayer assemblies. Biochimica et Biophysica Acta (BBA) Biomembranes 1860:2042-2063. DOI: 10.1016/J.BBAMEM.2018.02.026.

B W. 2021. Adjusting extracellular pH to prevent entry of SARS-CoV-2 into human cells. Genome 64:595-598. DOI: 10.1139/GEN-2020-0167.

Badrawy EM, El-Khier AN. 2018. Effect of sodium bicarbonate $8.4 \%$ on respiratory tract pathogens.

Baker AN, Richards SJ, Guy CS, Congdon TR, Hasan M, Zwetsloot AJ, Gallo A, Lewandowski JR, Stansfeld PJ, Straube A, Walker M, Chessa S, Pergolizzi G, Dedola S, Field RA, Gibson MI. 2020. The SARS-COV-2 Spike Protein Binds Sialic Acids and Enables Rapid Detection in a Lateral Flow Point of Care Diagnostic Device. ACS Central Science. DOI: 10.1021/acscentsci.0c00855.

Bennett WD, Henderson AG, Ceppe A, Zeman KL, Wu J, Gladman C, Fuller F, Gazda S, Button B, Boucher RC, Donaldson SH. 2020. Effect of hypertonic saline on mucociliary clearance and clinical outcomes in chronic bronchitis. ERJ Open Research 6:00269-02020. DOI: 10.1183/23120541.00269-2020.

Boucher RC, Stutts MJ, Bromberg PA, Gatzy JT. 1981. Regional differences in airway surface liquid composition. Journal of Applied Physiology 50:613-620. DOI: 10.1152/jappl.1981.50.3.613.

Bouvier NM, Palese P. 2008. The biology of influenza viruses. Vaccine 26:D49-53. DOI: 10.1016/j.vaccine.2008.07.039.

Bustamante-Marin XM, Ostrowski LE. 2017. Cilia and mucociliary clearance. Cold Spring Harbor Perspectives in Biology 9:a028241. DOI: 10.1101/cshperspect.a028241.

Casimir GJ, Lefèvre N, Corazza F, Duchateau J, Chamekh M. 2018. The acid-base balance and gender in inflammation: A mini-review. Frontiers in Immunology 9:475. DOI: 10.3389/fimmu.2018.00475.

Chakraborty I, Daniel K. 2020. Application of Alkaline Solution by a Nebulizer, Rotahaler and Inhaler in 
420

421

422

423

424

425

426

427

428

429

430

431

432

433

434

435

436

437

438

439

440

441

442

443

444

445

446

447

448

449

450

451

452

453

Prevention of Spread of Covid-19. CMRO 11:465-467. DOI: 10.15520/jcmro.v3i05.289.

Chand R, Swenson ER, Goldfarb DS. 2021. Sodium bicarbonate therapy for acute respiratory acidosis. Current opinion in nephrology and hypertension 30:223-230. DOI: 10.1097/MNH.0000000000000687.

Chen A, Dong L, Leffler NR, Asch AS, Witte ON, Yang L V. 2011. Activation of GPR4 by Acidosis Increases Endothelial Cell Adhesion through the cAMP/Epac Pathway. PLoS ONE 6. DOI: 10.1371/JOURNAL.PONE.0027586.

Clary-Meinesz C, Cosson J, Huitorel P, Blaive B. 1992. Temperature effect on the ciliary beat frequency of human nasal and tracheal ciliated cells. Biology of the Cell 76:335-338. DOI: 10.1016/02484900(92)90436-5.

Coronavirus disease (COVID-19): Vaccines. Available at https://www.who.int/news-room/q-adetail/coronavirus-disease-(covid-19)vaccines? adgroupsurvey $=\% 7$ Badgroupsurvey $\% 7 D \& g c l i d=C j 0 K C Q j w j P a C B h D k A R I$ SAISZN7TYn8 oHsE7htipYOxJUh2Yy8Ym8IOQ82ibzYNOVJs3lXJE5y35xgTYaAkHaEALw_wcB (accessed May 3, 2021).

COVID Action Platform | World Economic Forum. Available at https://www.weforum.org/platforms/covid-action-platform (accessed December 21, 2020).

COVID Live Update: 199,614,894 Cases and 4,249,394 Deaths from the Coronavirus - Worldometer. Available at https://www.worldometers.info/coronavirus/ (accessed August 3, 2021).

D’Amato M, Molino A, Calabrese G, Cecchi L, Annesi-Maesano I, D’Amato G. 2018. The impact of cold on the respiratory tract and its consequences to respiratory health. Clinical and Translational Allergy 8:20. DOI: 10.1186/s13601-018-0208-9.

Díaz FE, Dantas E, Geffner J. 2018. Unravelling the Interplay between Extracellular Acidosis and Immune Cells. Mediators of Inflammation 2018. DOI: 10.1155/2018/1218297.

Dollery SJ, Delboy MG, Nicola A V. 2010. Low pH-Induced Conformational Change in Herpes Simplex Virus Glycoprotein B. Journal of Virology 84:3759-3766. DOI: 10.1128/JVI.02573-09.

Dong L, Li Z, Leffler NR, Asch AS, Chi J-T, Yang L V. 2013. Acidosis Activation of the Proton-Sensing GPR4 Receptor Stimulates Vascular Endothelial Cell Inflammatory Responses Revealed by Transcriptome Analysis. PLOS ONE 8:e61991. DOI: 10.1371/JOURNAL.PONE.0061991.

Dong Y, Shamsuddin A, Campbell H, Theodoratou E. 2021. Current COVID-19 treatments: Rapid review of the literature. Journal of Global Health 11:1-22. DOI: 10.7189/JOGH.11.10003.

Eccles R. 2020. Respiratory mucus and persistence of virus on surfaces. Journal of Hospital Infection 105:350. DOI: 10.1016/j.jhin.2020.03.026.

ER O. 1993. Influence of $\mathrm{pH}$ on bacterial gene expression. Molecular microbiology 8:5-14. DOI: 
454

455

456

457

458

459

460

461

462

463

464

465

466

467

468

469

470

471

472

473

474

475

476

477

478

479

480

481

482

483

484

485

486

487

10.1111/J.1365-2958.1993.TB01198.X.

Fellenz MP, Gerweck LE. 1988. Influence of extracellular $\mathrm{pH}$ on intracellular $\mathrm{pH}$ and cell energy status: Relationship to hyperthermic sensitivity. Radiation Research 116:305-312. DOI: 10.2307/3577466. Focosi D, Maggi F. 2021. Neutralising antibody escape of SARS-CoV-2 spike protein: Risk assessment for antibody-based Covid-19 therapeutics and vaccines. Reviews in Medical Virology. DOI: 10.1002/RMV.2231.

Foxman EF, Storer JA, Fitzgerald ME, Wasik BR, Hou L, Zhao H, Turner PE, Pyle AM, Iwasaki A. 2015. Temperature-dependent innate defense against the common cold virus limits viral replication at warm temperature in mouse airway cells. Proceedings of the National Academy of Sciences of the United States of America 112:827-832. DOI: 10.1073/pnas.1411030112.

Frieman M, Baric R. 2008. Mechanisms of Severe Acute Respiratory Syndrome Pathogenesis and Innate Immunomodulation. Microbiology and Molecular Biology Reviews 72:672-685. DOI: 10.1128/mmbr.00015-08.

G la M, J B, S F, A M, L G, E C, G B, S DM, R G. 2021. Thermal inactivation of SARS COVID-2 virus: Are steam inhalations a potential treatment? Life sciences 265. DOI: 10.1016/J.LFS.2020.118801.

Gallagher PE, Arter AL, Krishnan B, Garcia-Espinosa MA, Tallant EA. 2013. Angiotensin II/Angiotensin-(1-7). In: Handbook of Biologically Active Peptides. Elsevier Inc., 494-501. DOI: 10.1016/B978-0-12-385095-9.00067-1.

Garcia JM, Lai JCC, Haselhorst T, Choy KT, Yen HL, Peiris JSM, von Itzstein M, Nicholls JM. 2014. Investigation of the binding and cleavage characteristics of $\mathrm{N} 1$ neuraminidases from avian, seasonal, and pandemic influenza viruses using saturation transfer difference nuclear magnetic resonance. Influenza and other Respiratory Viruses 8:235-242. DOI: 10.1111/irv.12184.

Glowacka I, Bertram S, Muller MA, Allen P, Soilleux E, Pfefferle S, Steffen I, Tsegaye TS, He Y, Gnirss K, Niemeyer D, Schneider H, Drosten C, Pohlmann S. 2011. Evidence that TMPRSS2 Activates the Severe Acute Respiratory Syndrome Coronavirus Spike Protein for Membrane Fusion and Reduces Viral Control by the Humoral Immune Response. Journal of Virology 85:4122-4134. DOI: 10.1128/jvi.02232-10.

Gomez CCS, Parazzi PLF, Clinckspoor KJ, Mauch RM, Pessine FBT, Levy CE, Peixoto AO, Ribeiro MÂGO, Ribeiro AF, Conrad D, Quinton PM, Marson FAL, Ribeiro JD. 2020. Safety, Tolerability, and Effects of Sodium Bicarbonate Inhalation in Cystic Fibrosis. Clinical Drug Investigation 40:105-117. DOI: 10.1007/s40261-019-00861-x.

Grasselli G, Zangrillo A, Zanella A, Antonelli M, Cabrini L, Castelli A, Cereda D, Coluccello A, Foti G, Fumagalli R, Iotti G, Latronico N, Lorini L, Merler S, Natalini G, Piatti A, Ranieri MV, Scandroglio AM, Storti E, Cecconi M, Pesenti A. 2020. Baseline Characteristics and Outcomes of 1591 Patients 
488

489

490

491

492

493

494

495

496

497

498

499

500

501

502

503

504

505

506

507

508

509

510

511

512

513

514

515

516

517

518

519

520

521

Infected with SARS-CoV-2 Admitted to ICUs of the Lombardy Region, Italy. JAMA - Journal of the American Medical Association 323:1574-1581. DOI: 10.1001/jama.2020.5394.

Gróf I, Bocsik A, Harazin A, Santa-Maria AR, Vizsnyiczai G, Barna L, Kiss L, Für G, Rakonczay Z, Ambrus R, Szabó-Révész P, Gosselet F, Jaikumpun P, Szabó H, Zsembery Á, Deli MA. 2020. The Effect of Sodium Bicarbonate, a Beneficial Adjuvant Molecule in Cystic Fibrosis, on Bronchial Epithelial Cells Expressing a Wild-Type or Mutant CFTR Channel. International Journal of Molecular Sciences 2020, Vol. 21, Page 4024 21:4024. DOI: 10.3390/IJMS21114024.

Harvey WT, Carabelli AM, Jackson B, Gupta RK, Thomson EC, Harrison EM, Ludden C, Reeve R, Rambaut A, Peacock SJ, Robertson DL. 2021. SARS-CoV-2 variants, spike mutations and immune escape. Nature Reviews Microbiology 2021 19:7 19:409-424. DOI: 10.1038/s41579-021-00573-0.

Helenius A. 2013. Virus entry: What has pH got to do with it? DOI: 10.1038/ncb2678.

Holsinger LJ, Nichani D, Pinto LH, Lamb RA. 1994. Influenza A virus M2 ion channel protein: a structure-function analysis. Journal of Virology 68:1551-1563. DOI: 10.1128/jvi.68.3.15511563.1994.

Integrated Biomedical Technology.Sodium Bicarbonate Chemistry. Available at http://www.ibtbiomed.com/tech_corner/pdf/sodium_bicarb.pdf(accessed August 4, 2021).

JA K. 2002. Fluid resuscitation and hyperchloremic acidosis in experimental sepsis: improved short-term survival and acid-base balance with Hextend compared with saline. Critical care medicine 30:300305. DOI: 10.1097/00003246-200202000-00006.

JL S, M F, M D, TA K. 2009. Cytoplasmic pH measurement and homeostasis in bacteria and archaea. Advances in microbial physiology 55. DOI: 10.1016/S0065-2911(09)05501-5.

Karamaoun C, Sobac B, Mauroy B, Van Muylem A, Haut B. 2018. New insights into the mechanisms controlling the bronchial mucus balance. PLOS ONE 13:e0199319. DOI: 10.1371/journal.pone.0199319.

Kellum JA, Song M, Li J. 2004. Science review: Extracellular acidosis and the immune response: Clinical and physiologic implications. Critical Care 8:331-336. DOI: 10.1186/cc2900.

Khan ZH, Sasaa MA, Mohammadi M, Alipour A, Hajipour A. 2020. Mortality Related to Intubation in Adult General ICUs: A Systematic Review and Meta-Analysis. Archives of Neuroscience 2020 7:3 7. DOI: $10.5812 /$ ANS.89993.

Kim C-H. 2020. SARS-CoV-2 Evolutionary Adaptation toward Host Entry and Recognition of Receptor O-Acetyl Sialylation in Virus-Host Interaction. International Journal of Molecular Sciences 21:4549. DOI: 10.3390/ijms21124549.

Krishnan S, Krishnan GP. 2021. N-Glycosylation Network Construction and Analysis to Modify Glycans on the Spike (S) Glycoprotein of SARS-CoV-2. Frontiers in Bioinformatics 0:15. DOI: 
522

523

524

525

526

527

528

529

530

531

532

533

534

535

536

537

538

539

540

541

542

543

544

545

546

547

548

549

550

551

552

553

554

555

10.3389/FBINF.2021.667012.

Larsson K, Tornling G, Gavhed D, Müller-Suur C, Palmberg L. 1998. Inhalation of cold air increases the number of inflammatory cells in the lungs in healthy subjects. European Respiratory Journal 12:825-830. DOI: 10.1183/09031936.98.12040825.

LD S, JS G, J D la P, K B, J F. 2008. Mortality after emergency department intubation. International journal of emergency medicine 1:131-133. DOI: 10.1007/S12245-008-0028-0.

Lever J, Altman RB. 2021. Analyzing the vast coronavirus literature with CoronaCentral. Proceedings of the National Academy of Sciences of the United States of America 118. DOI: 10.1073/PNAS.2100766118.

Liu H, Maruyama H, Masuda T, Honda A, Arai F. 2016. The Influence of Virus Infection on the Extracellular pH of the Host Cell Detected on Cell Membrane. Frontiers in Microbiology 7:1127. DOI: $10.3389 /$ fmicb.2016.01127.

LL C, L L, CY C, JP C, HW T, AW C, JD I, WM C, RR Z, X Z, AR T, DP L, WK T, TL Q, CC Y, KH C, VC C, KY Y, IF H, KK T. 2021. Impact of SARS-CoV-2 variant-associated RBD mutations on the susceptibility to serum antibodies elicited by COVID-19 infection or vaccination. Clinical infectious diseases : an official publication of the Infectious Diseases Society of America. DOI: 10.1093/CID/CIAB656.

LM T, RJ K. 2007. Hypertonic saline treatment of cystic fibrosis. The Annals of pharmacotherapy 41:481-484. DOI: 10.1345/APH.1H425.

Melamed ML, Horwitz EJ, Dobre MA, Abramowitz MK, Zhang L, Lo Y, Mitch WE, Hostetter TH. 2020. Effects of Sodium Bicarbonate in CKD Stages 3 and 4: A Randomized, Placebo-Controlled, Multicenter Clinical Trial. American Journal of Kidney Diseases 75:225-234. DOI: 10.1053/j.ajkd.2019.07.016.

Mercke U. 1975. The influence of varying air humidity on mucociliary activity. Acta Oto-Laryngologica 79:133-139. DOI: 10.3109/00016487509124665.

MH AA, LR R, ND G, KA S, AR H, DA S, J Z, MJ W. 2014. pH modulates the activity and synergism of the airway surface liquid antimicrobials $\beta$-defensin-3 and LL-37. Proceedings of the National Academy of Sciences of the United States of America 111:18703-18708. DOI: 10.1073/PNAS.1422091112.

Milanetti E, Miotto M, Di Rienzo L, Monti M, Gosti G, Ruocco G. 2020. In-Silico evidence for two receptors based strategy of SARS-CoV-2. bioRxiv:2020.03.24.006197. DOI: 10.1101/2020.03.24.006197.

Mody DBS. 2020. A clinical study to observe the effects of $8.4 \%$ Sodium Bicarbonate impregnated steam inhalation on Covid-19 infected patients. 
556

557

558

559

560

561

562

563

564

565

566

567

568

569

570

571

572

573

574

575

576

577

578

579

580

581

582

583

584

585

586

587

588

589

Mollica V, Rizzo A, Massari F. 2020. The pivotal role of TMPRSS2 in coronavirus disease 2019 and prostate cancer. Future Oncology 16:2029-2033. DOI: 10.2217/fon-2020-0571.

Nieto-Torres JL, DeDiego ML, Verdiá-Báguena C, Jimenez-Guardeño JM, Regla-Nava JA, FernandezDelgado R, Castaño-Rodriguez C, Alcaraz A, Torres J, Aguilella VM, Enjuanes L. 2014. Severe Acute Respiratory Syndrome Coronavirus Envelope Protein Ion Channel Activity Promotes Virus Fitness and Pathogenesis. PLoS Pathogens 10. DOI: 10.1371/journal.ppat.1004077.

Quade BN, Parker MD, Occhipinti R. 2021. The therapeutic importance of acid-base balance. Biochemical Pharmacology 183:114278. DOI: 10.1016/j.bcp.2020.114278.

Ren L, Zhang Y, Li J, Xiao Y, Zhang J, Wang Y, Chen L, Paranhos-Baccalà G, Wang J. 2015. Genetic drift of human coronavirus OC43 spike gene during adaptive evolution. Scientific Reports 5:1-8. DOI: $10.1038 /$ srep11451.

Ritchie H, Ortiz-Ospina E, Beltekian D, Mathieu E, Hasell J, Macdonald B, Giattino C, Appel C, RodésGuirao L, Roser M. 2020. Coronavirus Pandemic (COVID-19). Our World in Data.

Rowe SM, Miller S, Sorscher EJ. 2005. Cystic Fibrosis. New England Journal of Medicine 352:19922001. DOI: 10.1056/NEJMra043184.

S G, CJ S, OD R. 1991. Regulation of cytoplasmic pH in phagocytic cell function and dysfunction. Clinical biochemistry 24:241-247. DOI: 10.1016/0009-9120(91)80014-T.

S G, S M, A K, C K, R J, P B, D M, SK P. 2021. Promising phytochemicals of traditional Indian herbal steam inhalation therapy to combat COVID-19 - An in silico study. Food and chemical toxicology : an international journal published for the British Industrial Biological Research Association 148. DOI: 10.1016/J.FCT.2020.111966.

Saketkhoo K, Januszkiewicz A, Sackner MA. 1978. Effects of drinking hot water, cold water, and chicken soup on nasal mucus velocity and nasal airflow resistance. Chest 74:408-410. DOI: 10.1016/S0012-3692(15)37387-6.

Salganik M, Venkatakrishnan B, Bennett A, Lins B, Yarbrough J, Muzyczka N, Agbandje-McKenna M, McKenna R. 2012. Evidence for pH-Dependent Protease Activity in the Adeno-Associated Virus Capsid. Journal of Virology 86:11877-11885. DOI: 10.1128/jvi.01717-12.

Scheller C, Krebs F, Minkner R, Astner I, Gil-Moles M, Wätzig H. 2020. Physicochemical properties of SARS-CoV-2 for drug targeting, virus inactivation and attenuation, vaccine formulation and quality control. ELECTROPHORESIS 41:1137-1151. DOI: 10.1002/elps.202000121.

Schneider WM, Chevillotte MD, Rice CM. 2014. Interferon-Stimulated Genes: A Complex Web of Host Defenses. Annual Review of Immunology 32:513-545. DOI: 10.1146/annurev-immunol-032713120231.

Scudellari M. 2020. How the pandemic might play out in 2021 and beyond. Nature 584:22-25. DOI: 
10.1038/d41586-020-02278-5.

Shi C-S, Qi H-Y, Boularan C, Huang N-N, Abu-Asab M, Shelhamer JH, Kehrl JH. 2014. SARSCoronavirus Open Reading Frame-9b Suppresses Innate Immunity by Targeting Mitochondria and the MAVS/TRAF3/TRAF6 Signalosome. The Journal of Immunology 193:3080-3089. DOI: 10.4049/jimmunol.1303196.

Sodium Bicarbonate Injection Information - Drugs.com. Available at https://www.drugs.com/cdi/sodiumbicarbonate-injection.html (accessed August 3, 2021).

Stancioiu F, Papadakis GZ, Kteniadakis S, Izotov BN, Coleman MD, Spandidos DA, Tsatsakis A. 2020. A dissection of SARS-CoV2 with clinical implications (Review). International Journal of Molecular Medicine 46:489-508. DOI: 10.3892/ijmm.2020.4636.

Sturman LS, Ricard CS, Holmes K V. 1990. Conformational change of the coronavirus peplomer glycoprotein at $\mathrm{pH} 8.0$ and 37 degrees $\mathrm{C}$ correlates with virus aggregation and virus-induced cell fusion. Journal of Virology 64:3042-3050. DOI: 10.1128/jvi.64.6.3042-3050.1990.

Takeda M, Pekosz A, Shuck K, Pinto LH, Lamb RA. 2002. Influenza A Virus M2 Ion Channel Activity Is Essential for Efficient Replication in Tissue Culture. Journal of Virology 76:1391-1399. DOI: 10.1128/jvi.76.3.1391-1399.2002.

Teodori L, Sestili P, Madiai V, Coppari S, Fraternale D, Rocchi MBL, Ramakrishna S, Albertini MC. 2020. MicroRNAs Bioinformatics Analyses Identifying HDAC Pathway as a Putative Target for Existing Anti-COVID-19 Therapeutics. Frontiers in Pharmacology 0:1729. DOI: 10.3389/FPHAR.2020.582003.

The Role of Sodium Bicarbonate as Adjuvant Treatment of Computed Tomography Identified COVID-19 Pneumonia - Full Text View - ClinicalTrials.gov. Available at https://clinicaltrials.gov/ct2/show/NCT04374591 (accessed May 3, 2021).

Vallière C de, Wang Y, Eloranta JJ, Vidal S, Clay I, Spalinger MR, Tcymbarevich I, Terhalle A, Ludwig M-G, Suply T, Fried M, Kullak-Ublick GA, Frey-Wagner I, Scharl M, Seuwen K, Wagner CA, Rogler G. 2015. G Protein-coupled pH-sensing Receptor OGR1 Is a Regulator of Intestinal Inflammation. Inflammatory Bowel Diseases 21:1269. DOI: 10.1097/MIB.0000000000000375.

Wardeh A, Conklin J, Ko M. 2020. Case reports of observed significant improvement in patients with ARDS due to COVID-19 and maximum ventilatory support after inhalation of sodium bicarbonate. Journal of Clinical Intensive Care and Medicine 5:015-019. DOI: 10.29328/journal.jcicm.1001029.

Wark P, Mcdonald VM. 2018. Nebulised hypertonic saline for cystic fibrosis. Cochrane Database of Systematic Reviews 2018. DOI: 10.1002/14651858.CD001506.pub4.

Williams R, Rankin N, Smith T, Galler D, Seakins P. 1996. Relationship between the humidity and temperature of inspired gas and the function of the airway mucosa. Critical Care Medicine 24:1920- 
624

625

626

627

628

629

630

631

632

633

634

635

636

637

638

639

640

641

642

643

644

645

646

647

648

649 .

1929. DOI: $10.1097 / 00003246-199611000-00025$.

WL E, KB G, SP M, TL C. 1991. Inhalation of an alkaline aerosol by subjects with mild asthma does not result in bronchoconstriction. The American review of respiratory disease 143:341-345. DOI: 10.1164/AJRCCM/143.2.341.

YAMAGUCHI T, KOGA M, FUJITA Y, KIMOTO E. 1982. Effects of pH on Membrane Fluidity of Human Erythrocytes. The Journal of Biochemistry 91:1299-1304. DOI: 10.1093/OXFORDJOURNALS.JBCHEM.A133815.

Yamaya M, Shimotai Y, Hatachi Y, Homma M, Nishimura H. 2016. serine-proteases-and-theirinhibitors-in-human-airway-epithelial-cells-effectson-influenza-virus-replication-and-airway-serinepro-2327-5073-1000238. DOI: 10.4172/2327-5073.1000238.

Yang J, Petitjean SJL, Koehler M, Zhang Q, Dumitru AC, Chen W, Derclaye S, Vincent SP, Soumillion P, Alsteens D. 2020. Molecular interaction and inhibition of SARS-CoV-2 binding to the ACE2 receptor. Nature Communications 2020 11:1 11:1-10. DOI: 10.1038/s41467-020-18319-6.

Yuan P, Yang Z, Song H, Wang K, Yang Y, Xie L, Huang S, Liu J, Ran L, Song Z. 2018. Three Main Inducers of Alphacoronavirus Infection of Enterocytes: Sialic Acid, Proteases, and Low pH. Intervirology 61:53-63. DOI: 10.1159/000492424.

Zamorano Cuervo N, Grandvaux N. 2020. ACE2: Evidence of role as entry receptor for SARS-CoV-2 and implications in comorbidities. eLife 9. DOI: 10.7554/eLife.61390.

Zanin M, Baviskar P, Webster R, Webby R. 2016. The Interaction between Respiratory Pathogens and Mucus. Cell Host and Microbe 19:159-168. DOI: 10.1016/j.chom.2016.01.001.

Zipeto D, Palmeira J da F, Argañaraz GA, Argañaraz ER. 2020. ACE2/ADAM17/TMPRSS2 Interplay May Be the Main Risk Factor for COVID-19. Frontiers in Immunology 11:2642. DOI: 10.3389/fimmu.2020.576745. (1) 
Figure 1

Warm Sodium Bicarbonate (SB) inhalation modifies airway microenvironment fighting COVID-19 progression.

The treatment contemplates, twice daily, $1 \mathrm{~L}$ of water with $20 \mathrm{~g}$ of SB that should be brought to the boil. When heat has been turned off, the head should be placed at $30-40 \mathrm{~cm}$ covered with a cloth to breath normally for $15 \mathrm{~min}$.

\section{Proposal of intervention study}

\section{Extracellular PH} modification

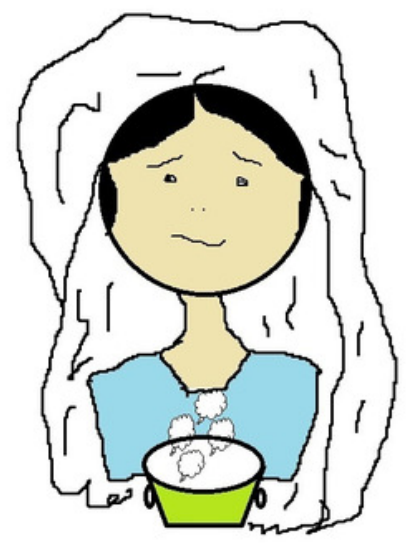

WARM SB INHALATION
Osmolarity hypertonic extracellular enviroment
Extracellular

temperature increase 
Figure 2

Warm Sodium Bicarbonate (SB) inhalation therapy steps that may help to contrast SARS-COV-2 infection and COVID-19 progression.

The therapy may be used as pre-exposure/exposure prophylaxis, as adjunctive therapy (either during SARS-COV2 infection and COVID-19 disease progression) or added in oxygen ventilator devices for severe COVID-19 patients.

$\begin{array}{ccccc}\begin{array}{c}\text { PROBABLE } \\ \text { EXPOSURE } \\ \text { TO VIRUS }\end{array} & \begin{array}{c}\text { EXPOSURE } \\ \text { TO VIRUS }\end{array} & \begin{array}{c}\text { SARS-COV2 } \\ \text { INFECTION }\end{array} & \text { COVID-19 } & \begin{array}{c}\text { SEVERE } \\ \text { COVID-19 }\end{array} \\ \begin{array}{c}\text { Pre-exposure } \\ \text { prophylaxis }\end{array} & \begin{array}{c}\text { Exposure } \\ \text { prophylaxis }\end{array} & \begin{array}{c}\text { Adjunctive } \\ \text { therapy or } \\ \text { COVID-19 } \\ \text { preventive } \\ \text { prophylaxis }\end{array} & \begin{array}{c}\text { Adjunctive } \\ \text { therapy }\end{array} & \begin{array}{c}\text { SB addition in } \\ \text { oxygen } \\ \text { ventilator } \\ \text { devices }\end{array} \\ & & & \end{array}$

